\title{
Study on waste heat recovery from exhaust gas spark ignition (S.I.) engine using steam turbine mechanism
}

\author{
Kamarulhelmy Talib ${ }^{1, *}$, Safarudin G. Herawan ${ }^{1,2}$, Musthafah M. Tahir ${ }^{1,2}$, Azma Putra $^{1,2}$, and \\ Shamsul A. Shamsudin ${ }^{1,2}$ \\ ${ }^{1}$ Faculty of Mechanical Engineering, Universiti Teknikal Malaysia Melaka, Hang Tuah Jaya, 76100 \\ Durian Tunggal, Melaka, Malaysia. \\ ${ }^{2}$ Centre for Advanced Research on Energy, Universiti Teknikal Malaysia Melaka, Hang Tuah Jaya, \\ 76100 Durian Tunggal, Melaka, Malaysia.
}

\begin{abstract}
The issue of global warming has pushed the effort of researchers not only to find alternative renewable energy, but also to improve the machine's energy efficiency. This includes the utilization of waste energy into 'useful energy'. For a vehicle using internal combustion engine (ICE), the waste energy produce by exhaust gas can be utilize to 'useful energy' up to $34 \%$. The energy from the automotive exhaust can be harness by implementing heat pipe heat exchanger in the automotive system. In order to maximize the amount of waste energy that can be turned to 'useful energy', the used of appropriate fluid in the heat exchanger is important. In this study, the fluid used is water, thus converting the fluid into steam and thus drive the turbine that coupling with generator. The paper will explore the performance of a naturally aspirated spark ignition (S.I.) engine equipped with waste heat recovery mechanism (WHRM) that used water as the heat absorption medium. The experimental and simulation test suggest that the concept is thermodynamically feasible and could significantly enhance the system performance depending on the load applied to the engine.
\end{abstract}

\section{Introduction}

Years by years, the number of motor vehicles in the world continues to grow globally and therefore increases the reliance on the petroleum and increases the release of carbon dioxide into atmosphere. Eventually, this will contribute to global warming and the increase of earth's temperature. To overcome this trend, new vehicle technologies must be introduced to achieve better fuel economy consumption without increasing harmful gaseous emissions. For internal combustion engine (ICE) in most typical gasoline fuelled vehicles, for a typical $2.0 \mathrm{~L}$ gasoline engine used in passenger cars, it was estimated that $21 \%$ of the fuel energy is wasted through the exhaust at the most common load and speed range [1]. The rest of the fuel energy is lost in the form of waste heat in the coolant, as well as friction and parasitic losses.

\footnotetext{
${ }^{*}$ Corresponding author: helmy2127@gmail.com
} 
Nowadays, the requirement of electric loads in a vehicle are increasing due to improvements of comfort, driving performance, and power transmission. Therefore, it is of interest to utilize the wasted energy by developing the heat recovery mechanism of exhaust gas from internal combustion engine. It has been identified in [2] that the temperature of the exhaust gas varies depending on the engine load and engine speed. As the engine speed increases, the temperature of the exhaust gas will also increase. By implementing heat recovery concept in the vehicle, a significant amounts of energy that would normally, be lost via engine exhaust can thus be recovered into electrical energy. Theoretically, the energy that loss from the exhaust can be recovered to supply an extra power source for vehicles. Thus will result in lowering fuel consumption, greater efficiency, and overall reduction in greenhouse gas emission.

The technologies on waste heat recovery of IC engine is consist of low grade heat from cooling system and high grade heat from exhaust system. For low grade waste heat, the Organic Rankine Cycle is the favourite choice to recover waste heat energy [3], whereas high grade heat, several techniques of recover the energy are applied such as thermoelectric generator [4], turbocharger [5], turbo-compound [6], Rankine cycle system [7], heat pipe [8], air conditioning [8], heat exchanger for thermal energy storage [9], and heat exchanger for fuel conservation, emission reduction [10], and power turbine of waste heat recovery mechanism [11]. The approaches either by theoretical, simulation or experimental works it leads to improve the brake fuel consumption that generated better overall efficiency.

Based on the application of waste heat recovery that are more attractive to be explored are turbocharger, and turbo-compound due to the simple construction and less cost. This is because the potential to produce output power and improve BSFC and efficiency are promising. To improve the performance of turbocharger, several studies [5, 11] used electrical motor assisted or Integrated Starter Generator (ISG) to turbocharger or to parallel hybrid power system on a diesel engine [11]. The aim of this method is to improve the fuel economy of diesel Homogeneous Charge Compression Ignition (HCCI), and the results are the fuel economy, the soot emission and NOx emission are improved by $10.9 \%, 6 \%$ and $12.1 \%$ respectively [11]. The electrical motor assisted turbocharger is the integration of a high-speed $7.5 \mathrm{~kW}$ electric motor-generator within a standard turbocharger of a heavy-duty vehicle, which the purpose of this system is to improve the fuel economy and turbo-lag. As a result, this system on an urban bus, the fuel economy can be improved by up to $6 \%$ or above depending on the actual driving cycle and an electrical assist motor can reduce turbolag by typically $50 \%$ [12].

\section{Experimental setup}

\subsection{Design of experiment}

The experiment was performed on a Toyota vehicle having 1.6 litre in-line four-cylinder gasoline engines. Table 1 shows the specification of the test engine. A schematic diagram of the experimental setup is shown in Figure 1. A 75 Watt bulb were used as a load causing the DC generator to produce an output current and voltage which were recorded in a computer through USB digital multimeter. The air duct to the intake manifold of engine was equipped with a pitot tube digital anemometer to measure the volume flow rate of the intake air. The engine speed and the WHRM turbine speed were continuously monitored using an optical tachometer allowing the digital data to be recorded in a computer through USB data acquisition module. This was also applied for the data of the throttle position for intake air captured using the existing throttle sensor in the experimental vehicle. The test was conducted on the road with variable vehicle speed up to $70 \mathrm{~km} / \mathrm{h}$ with normal driving 
and full throttle driving to measure the performance of engine with and without WHRM. Some features of the instrumentation are summarized in Table 2. To determine the performance of engine on the full throttle driving, a simulation program is needed. This simulation is created under Matlab Simulink environment. The program is using demo Simulink program [13] with some modification to suit the target. From the simulation, we can get the power and torque of the engine experimental vehicle. The results are needed to compare between before and after implementation of waste heat recovery mechanism, which then can see whether these mechanisms affect the performance of engine or not. Figure-2 shows the original demo program Simulink and some modification had been made.

Table 1. Specification of the test engine.

\begin{tabular}{|c|c|}
\hline Type & Specification \\
\hline Valve train & DOHC 16 valves \\
\hline Fuel system & Multi point fuel injection \\
\hline Displacement & 1587 cc (in-line) \\
\hline Compression ratio & $9: 4: 1$ \\
\hline Bore & $81 \mathrm{~mm}$ \\
\hline Stroke & $77 \mathrm{~mm}$ \\
\hline Power & $112 \mathrm{Hp} @ 6600 \mathrm{rpm}$ \\
\hline Torque & $131 \mathrm{Nm} @ 4800 \mathrm{rpm}$ \\
\hline
\end{tabular}

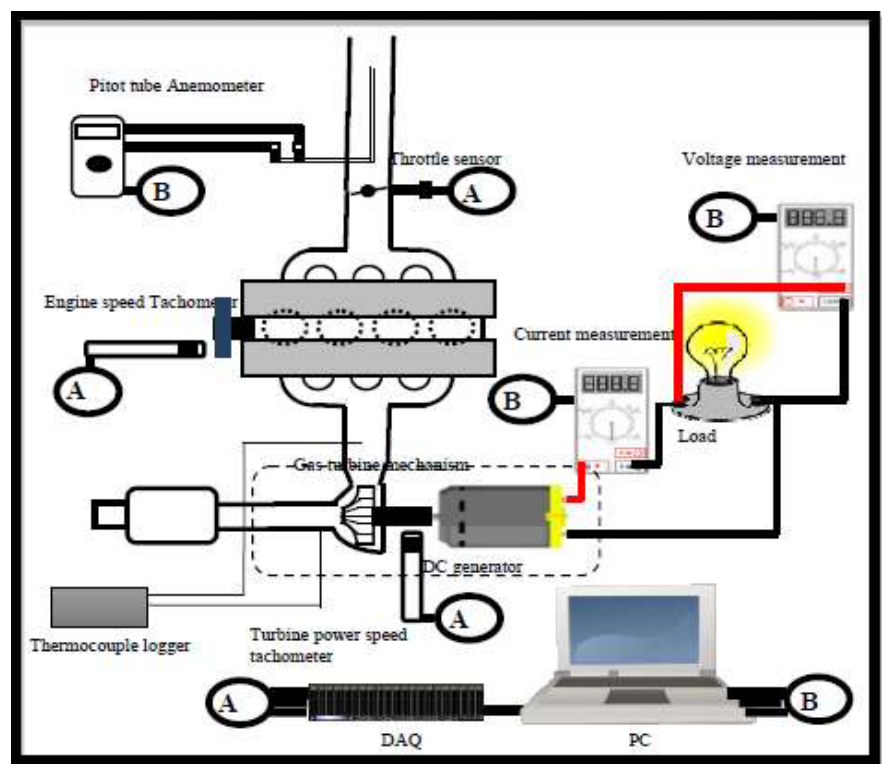

Fig. 1. Schematic layout of the experimental setup of waste heat recovery mechanism. 


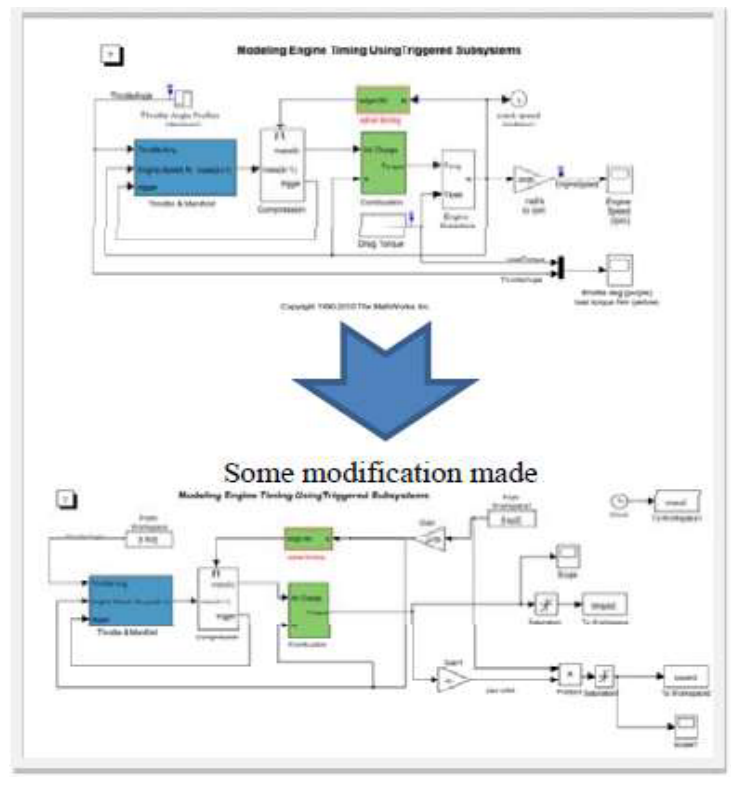

Fig. 2. Modified Demo Simulink Program.

\subsection{Experimental procedure}

One of the thing that make this project different from other waste heat recovery experimental is the data gather from the project is obtain from real condition, on the real road track without any controllable variable. The only constant variable is the track of the road test is same, that situated at Auto-City, MITC, Melaka as shown in Figure 3.

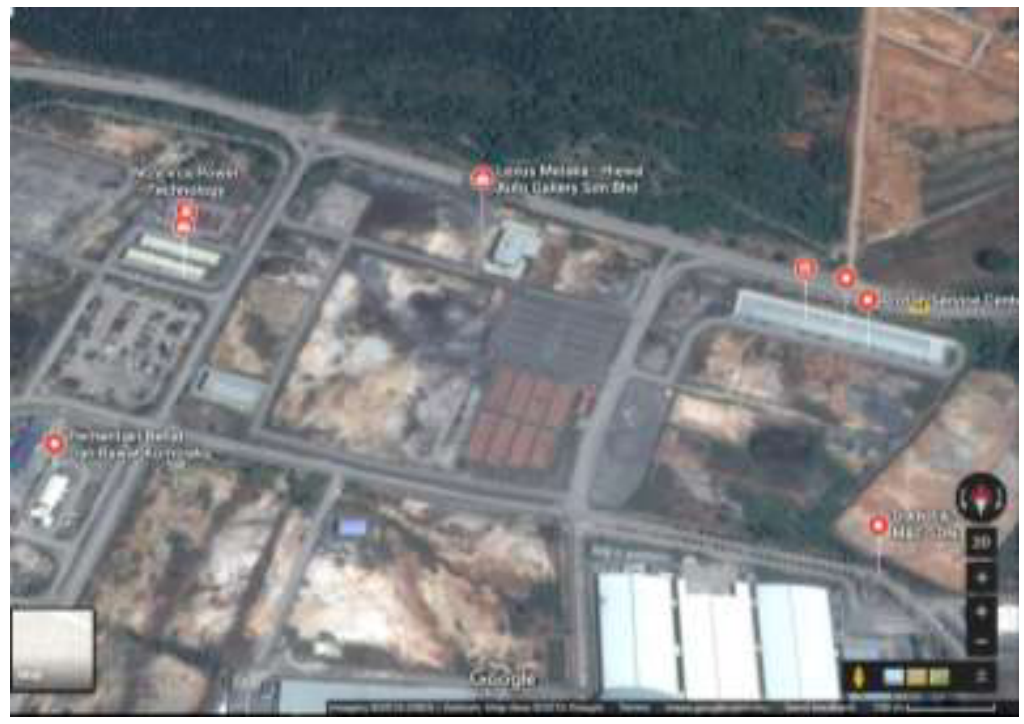

Fig. 3. The plan of the experiment track.

A 75 Watt bulb were used as a load causing the DC generator to produce an output current and voltage. The value of the current and voltage will then be recorded in a computer through USB digital multimeter. In this experiment, up to four 75 Watt bulbs will 
be used in order to generate bigger current and voltage values. As the number of the bulbs increases, the load given to the DC generator increases thus the value of current and voltage produces will also increase. The experiment is design to be run in ten (10) rounds as shown in Figure 4.

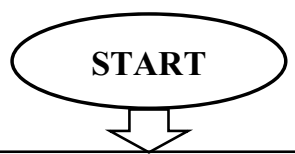

Round 1 and 2 - Free Load:

1) Round 1, the car will run on the track with normal speed average $60-70$ $\mathrm{km} / \mathrm{h}$.

2) Round 2, there will be full-throttle acceleration (start point as shown in Figure 4) for about 8 seconds.

3) After that, the car will stop and added with one load (75 Watt bulb).

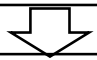

Round 3 and 4 - One Load (75 Watt bulb):

1) Round 3, the car will run on the track with normal speed average $60-70$ $\mathrm{km} / \mathrm{h}$.

2) Round 4, there will be full-throttle acceleration (start point as shown in Figure 4) for about 8 seconds.

3) After that, the car will stop and added with one load (75 Watt bulb).

Round 5 and $6-2$ Loads (75 Watt bulb):

1) Round 5, the car will run on the track with normal speed average $60-70$ $\mathrm{km} / \mathrm{h}$.

2) Round 6, there will be full-throttle acceleration (start point as shown in Figure 4) for about 8 seconds.

3) After that, the car will stop and added with one load (75 Watt bulb).

Round 7 and $8-3$ Loads (75 Watt bulb):

1) Round 7, the car will run on the track with normal speed average $60-70$ $\mathrm{km} / \mathrm{h}$.

2) Round 8, there will be full-throttle acceleration (start point as shown in Figure 4) for about 8 seconds.

3) After that, the car will stop and added with one load (75 Watt bulb).

Round 9 and $10-4$ Loads (75 Watt bulb):

1) Round 9, the car will run on the track with normal speed average $60-70$ $\mathrm{km} / \mathrm{h}$.

2) Round 10, there will be full-throttle acceleration (start point as shown in Figure 4) for about 8 seconds.

3) After that, the car will stop and added with one load (75 Watt bulb).

Fig. 4. Flowchart of the road test.

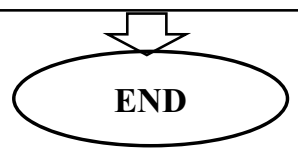




\section{Results and discussion}

Figure 5, Figure 6 and Figure 7 shows the heat energy come out from the exhaust gas on experimental vehicle in terms of engine speed, exhaust temperature, air flow rate and throttle angle.

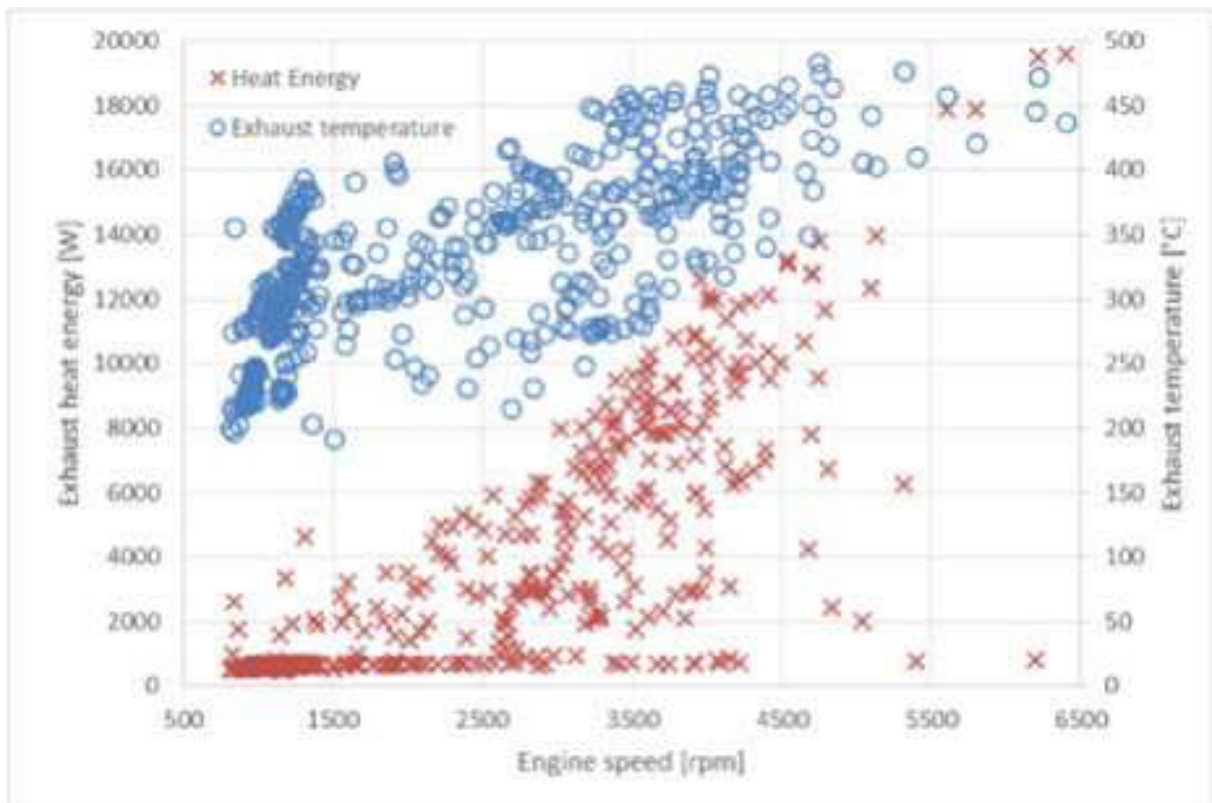

Fig. 5. Heat energy from exhaust gas of experimental vehicle on engine speed and exhaust temperature.

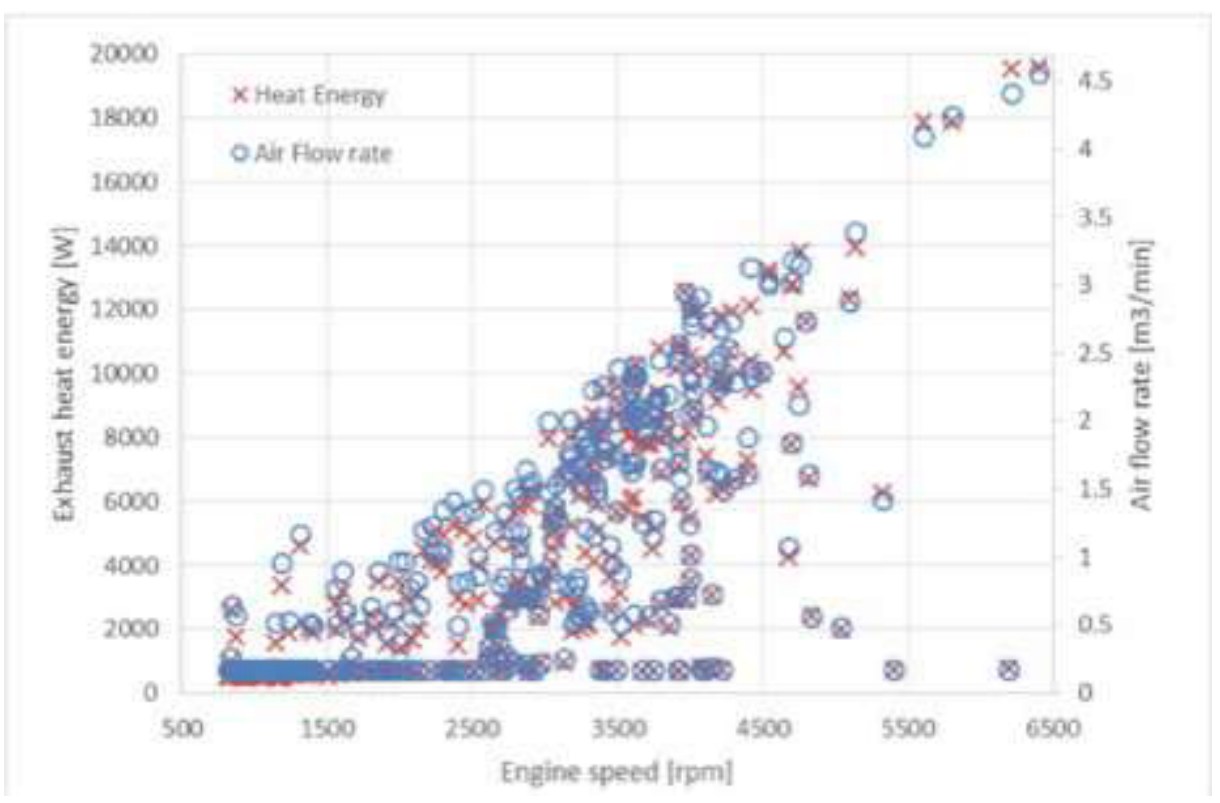

Fig. 6. Heat energy from exhaust gas of experimental vehicle on engine speed and air flow rate. 


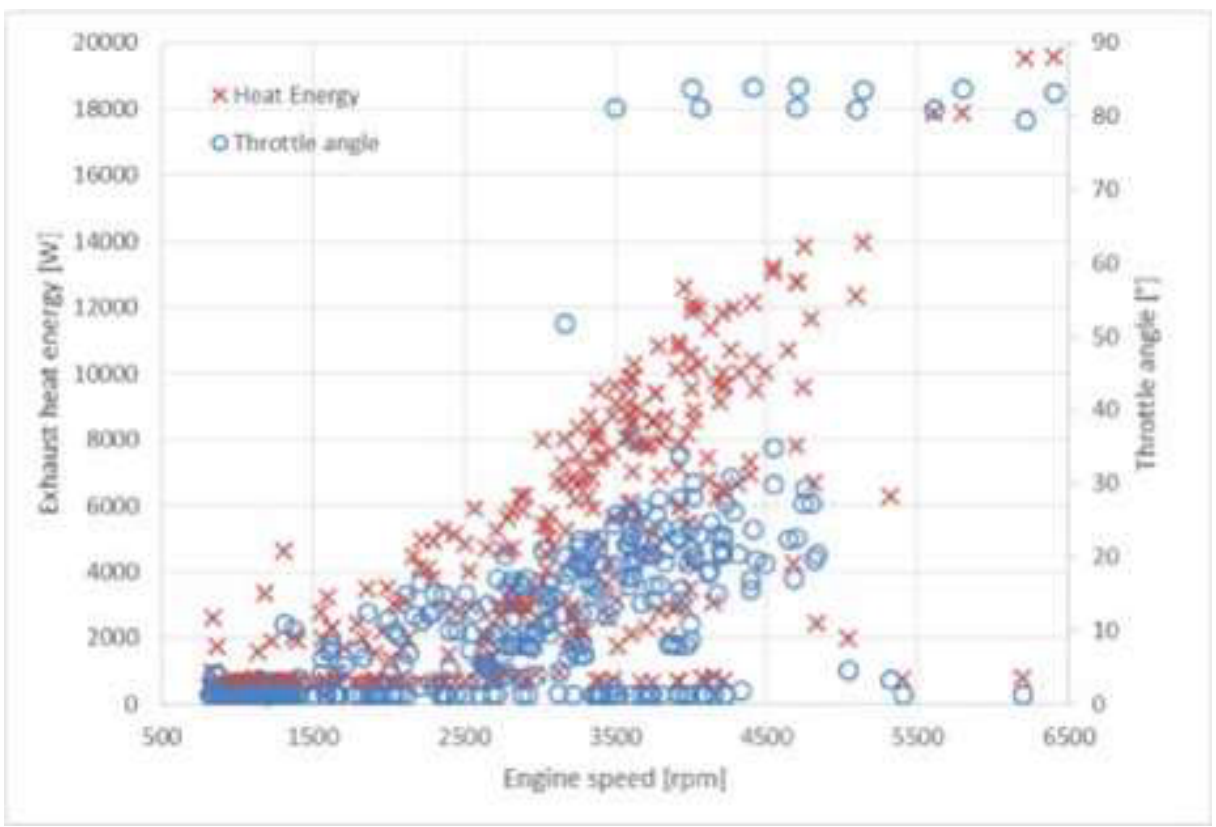

Fig. 7. Heat energy from exhaust gas of experimental vehicle on engine speed and throttle angle.

Theoretically, the heat energy produced from the exhaust is depending on the engine speed and exhaust temperature. As the engine speed increases, the exhaust temperature will increase. However, there are some behaviours that not accomplish with this argument. This is because the road test was conducted on-road test where no parameters were being controlled. The measurement is solely based on the normal driving and full throttle driving on the road, resulting both dynamic and transient conditions. The heat energy from exhaust is varies in the range of $500 \mathrm{~W}$ up to almost $23 \mathrm{~kW}$, which is a good agreement with [14] where the heat energy is in the range of $5 \mathrm{~kW}$ and can reach up to $23 \mathrm{~kW}$. Air flow rate give a significant effect on the heat energy as almost each single data of both parameters are match each other. Even though engine speed and exhaust temperature are high, but the air flow rate is low. The heat energy follows the air flow rate consistently.

In term of throttle angle, as the throttle angle increases, the heat energy will also increases as shown in Figure 7. By applying range of 10 to 30 degree on the normal driving, the heat energy produce is in the range of $2 \mathrm{~kW}$ to $12 \mathrm{~kW}$. However, at the angle of almost 90 degrees (full throttle angle), not all the heat in the maximum value. This is once again due to the actual driving on the road as dynamic and transient conditions. Therefore, to optimize the heat energy from exhaust, the engine speed, exhaust temperature, throttle angle and air flow rate to be increases. As all these parameters be in optimum value, the heat energy from the exhaust can be generated at the optimum condition. It is obvious that the waste heat produced from the exhaust is high. Thus, it is significant and worthy to recover this wasted energy.

Figure 8 shows the measured data of the parameters which have already combined between the normal driving test and full throttle test. As seen in Figure 8, correlations between all the four parameters (engine speed, exhaust temperature, throttle angle, and air flow rate) can be clearly observed. The higher the value of throttle angle, the higher the air flow rate and thus increases the speed of the engine. The change of throttle angle also directly affects the WHRM turbine speed, which eventually changes the output current and voltage accordingly. 

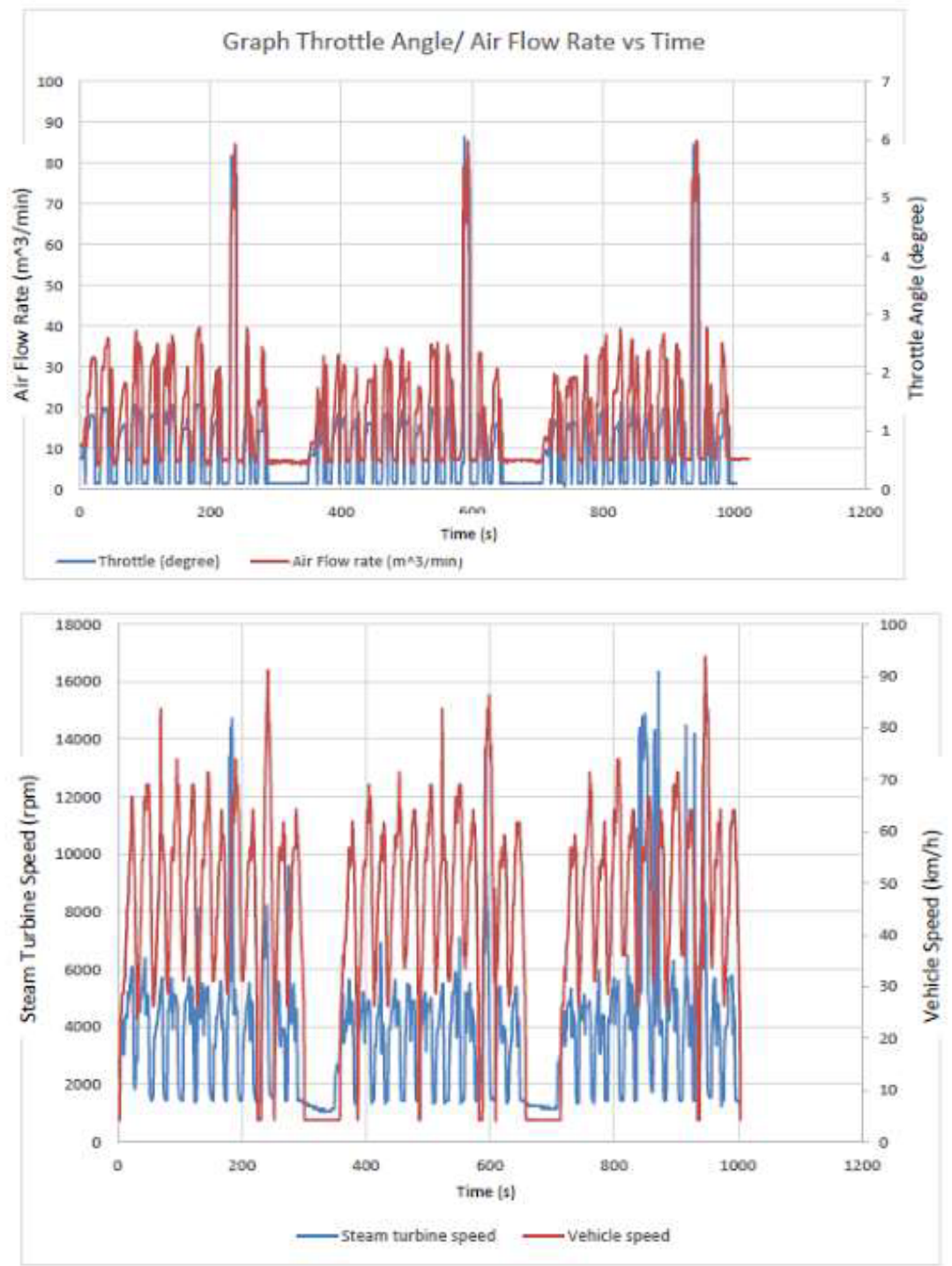

Fig. 8. The measured data from the experimental vehicle with WHRM.

Figure 9 shows the voltage produced from WHRM when applied two loads and three loads of 75 Watt bulbs. From the graph, the maximum voltage that produce by two loads and three loads are $21.04 \mathrm{~V}$ and $33.32 \mathrm{~V}$ respectively. This prove as the number of loads increases, the voltage produce will also increase and lead to producing higher power output. 


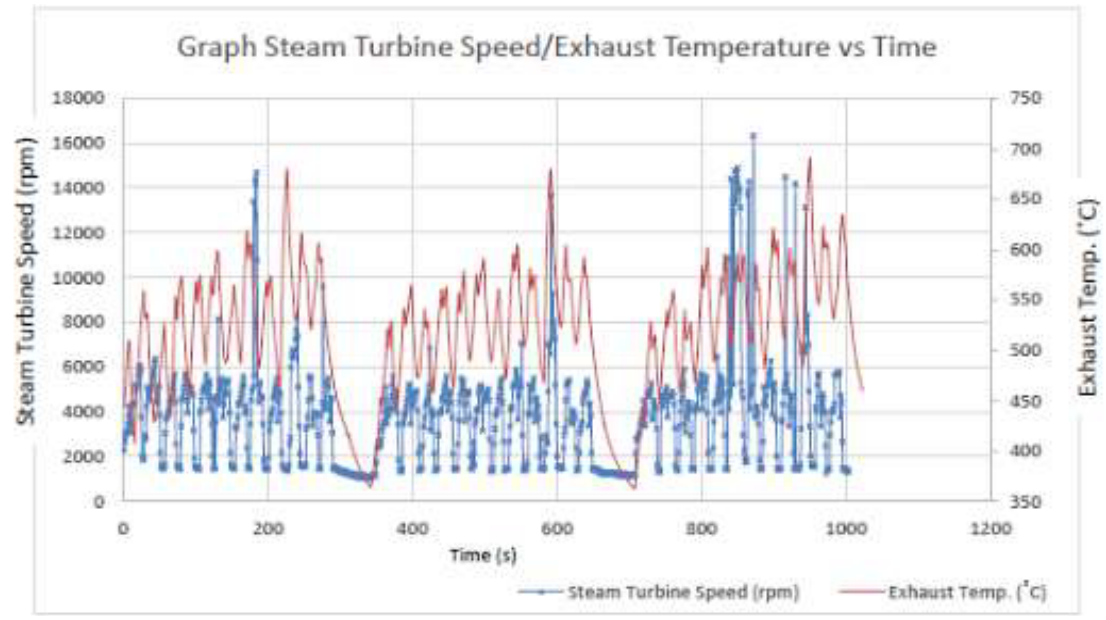

Fig. 9. Voltage produced from WHRM.

\section{Conclusions}

Utilization of waste heat energy from exhaust gas using WHRM system in a S.I. engine has been reported. The system is proved to produce voltage up to $33.32 \mathrm{~V}$ at normal driving conditions. The proposed system could become a potential energy recovery that can be stored in auxiliary battery and used for electrical appliances in automotive vehicle.

The authors would like to acknowledge the Universiti Teknikal Malaysia Melaka (UTeM) and Ministry of Higher Education Malaysia, for funding support and facilities through the Fundamental Research Grant Scheme (FRGS) no. FRGS/2/2014/TK06/FKM/02/F00236.

\section{References}

1. R.E. Chammas and D. Clodic, Combine cycle for hybrid vehicle, SAE Paper 2005, 01, $1171(2005)$

2. Z. Peng, T. Wang, Y. He, X. Yang, L. Lu, Analysis of environmental and economic benefits of integrated Exhaust Energy Recovery (EER) for vehicles, Applied Energy, 105, 238-243, (2013)

3. A. A. Boretti, Transient operation of internal combustion engines with Rankine waste heat recovery systems, Applied Thermal Engineering, 36, 18-23, (2012)

4. J. Serrano, V. Dolz, R. Novella, A. Garcia, DH diesel engine equipped with a bottoming Rankine cycle as waste heat recovery system, Part 2: Evaluation of alternative solution, Applied Thermal Engineering, 36, 279-287 (2012)

5. F. Yang, G. Gao, M. Ouyang, L. Chen, Y. Yang, Research on a diesel HCCI engine assisted by an ISG motor, Applied Energy, 101, 718-79, (2013)

6. R. Zhao, W. Zhuge, Y. Zhang, Y. Yin, Z. Chen, Z. Li, Parametric study of power turbine for diesel engine waste heat recovery, Applied Thermal Engineering, 67(1), 308319, (2014)

7. T. Wang, Y. Zhang, J, Zhang, G. Shu, Z. Peng, Analysis of recoverable exhaust energy from a light-duty gasoline engine, Applied Thermal Energy, 53(2), 414-419, (2013)

8. F. Yang, X. Yuan, G. Lin, Waste heat recovery using heat pipe heat exchanger for heating automobile using exhaust gas, Applied Thermal Energy, 23(3), 367-372, (2003)

9. P. Kauranen, T. Elonen, L. Wikstrom, K. Heikkinen, J. Laurikko, Temperature optimisation of a diesel engine using exhaust gas heat recovery and thermal energy 
storage (diesel engine with thermal energy storage), Applied Thermal Energy, 30(6), 631-638, (2010)

10. F. Will, Fuel conservation and emission reduction through novel waste heat recovery for internal combustion engines, Fuel, 102, 247-255, (2012)

11. S. G. Herawan, A. H. Rohhaizan, A. Putra, A. F. Ismail, Prediction of Waste Heat Energy Recovery Performance in a Naturally Aspirated Engines Using Artificial Neural Network, ISRN Mechanical Engineering, (2014)

12. J. Bumby, E. Spooner, J. Carter, Electrically assisted turbochargers; their potential for energy recovery, 2016

13. T. MathWorks, Matlab, The MathWorks, Natick, MA, (2009)

14. N. Yamada, M.N. Mohamad, Efficiency of hydrogen internal combustion engine combined with open steam Rankine cycle recovering water and waste heat, International Journal of Hydrogen Energy. 35(3), 1430-1442, (2010) 